\title{
HURTOWNIA DANYCH Z BAZĄ WIEDZY \\ W DYNAMICZNYM ZARZAZDZANIU PRZEDSIĘBIORSTWEM
}

\author{
BOŻENA ŚMIAŁKOWSKA ${ }^{1}$ \\ Zachodniopomorski Uniwersytet Technologiczny w Szczecinie \\ Wydział Informatyki \\ ${ }^{1}$ e-mail: bsmialkowska@wi.zut.edu.pl
}

SŁOWA KLUCZOWE

STRESZCZENIE adaptacyjna hurtownia danych, zarządzanie dynamiczne, systemy wspomagania decyzji wiedzą

W artykule zaprezentowano model systemu komputerowego wspomagania dynamicznego zarządzania przedsiębiorstwem z użyciem bazy wiedzy, adaptacyjnej hurtowni danych oraz dynamicznego modelu funkcjonowania firmy. Aby hurtownia spełniła swoją funkcję, musi być wyposażona w mechanizmy adaptacyjnego i nadążnego dopasowania do zmiennych potrzeb informacyjnych firmy, musi dostarczać historycznych danych $z$ dotychczasowej działalności firmy, danych o realizacji strategii firmy, danych o współczynnikach dopasowania firmy do jej otoczenia a także musi dostarczać wyników z symulacji prognozowanych scenariuszy biznesowych. By system $z$ hurtownią danych realizował funkcje związane $\mathrm{z}$ dynamicznym zarządzaniem, powinna być ona wyposażona dodatkowo w zbiór metod wnioskowania, które z repozytorium wiedzy deklaratywnej (np. strategia firmy) oraz wiedzy proceduralnej opartej na gromadzonych w hurtowni danych tworzących tzw. tablice identyfikacji stanu firmy w jej otoczeniu biznesowym umożliwią wnioskowanie, wywód konkluzji (reguł) i wiedzy wspomagającej tym samym dynamiczne zarządzanie firmą.

\section{Wprowadzenie}

Sukcesy biznesowe przedsiębiorstwa zależą od metod i koncepcji jego zarządzania. Jedną z takich koncepcji jest tzw. zarządzanie dynamiczne. Polega ono na takim zarządzaniu, które umożliwia szybką (dla sytuacji krytycznych natychmiastową) reakcję na zmienne w czasie warunki działania firmy z punktu widzenia otoczenia biznesowego firmy jak również jej wewnętrznych potrzeb poprzez adaptację procesów działań w firmie, opartą na wiedzy 
(Lozano, 2000). Jest to forma zarządzania biznesowego ukierunkowana na tzw. organizację uczącą się. Istotnymi elementami takiego zarządzania jest, obok czasu reakcji, dostęp do wiedzy i to w takiej formie, by możliwe było skuteczne oddziaływanie czy wnioskowanie.

Pod pojęciem reprezentacji wiedzy rozumie się tu sposób przedstawienia wiedzy, zwykle w formie jej struktury (np. za pomocą języka formalnego), znaczenia (interpretacji) oraz wnioskowania, w ramach którego wykorzystuje się ją do wyprowadzenia wniosków niezbędnych w procesach zarządczych. W literaturze (Moczulski, 2000) wyróżnia się tzw. wiedzę proceduralną lub deklaratywną, które są formą struktury wiedzy.

W systemach opartych na wiedzy, a raczej bazie wiedzy, istotna jest nie tylko reprezentacja wiedzy, ale również jej pozyskiwanie (akwizycja), sposób użycia czy objaśnianie.

Wiedza w warunkach rzeczywistych wiąże się z niepewnością i jest zmienna w czasie. Przyczyn niepewności wiedzy jest wiele. Zwykle upatruje się ich w niewiarogodnych źródłach informacji, różnorodności znaczeniowej opisu wiedzy w językach formalnych, sprzeczności informacji, z których wywodzi się wiedzę, zmienności sytuacji decyzyjnej w czasie, starzeniu się danych czy wiedzy, nieznanych czynnikach wpływających na proces wnioskowania czy akwizycji wiedzy. Obok problemów z niepewnością wiedzy równie istotnym aspektem procesów związanych z zarządzaniem dynamicznym jest czas niezbędny do realizacji tych procesów, a także czas, $w$ jakim podejmuje się te procesy.

Głównymi środkami wspomagającymi procesy zarządzania dynamicznego są: dynamiczny (zależny od czasu) model firmy w jej biznesowym otoczeniu, a także systemy komputerowego wspomagania, zwłaszcza te ukierunkowane na gromadzenie i udostępnianie danych oraz wiedzy. Spójną koncepcję takiego wspomagania zaprezentowano w kolejnych rozdziałach artykułu.

\section{Dynamiczny model funkcjonowania fipmy w jej biznesowym otoczeniu}

Opierając się na przesłankach systemowych i funkcjonalnych zaprezentowanych w literaturze (Konieczny, 1983; Śmiałkowska, 1985, 2009) można utworzyć model funkcjonalny firmy (systemu) w jej biznesowym otoczeniu, uwarunkowany czasem. Zgodnie z tymi podejściami otoczeniem biznesowym firmy są inne firmy, przedsiębiorstwa, organizacje społeczne, gospodarcze lub prawne, które ją zasilają w energię, środki produkcji, materiały, ludzi, informacje itp., niezbędne do jej funkcjonowania na rynku, oraz przedsiębiorstwa, organizacje społeczne, gospodarcze lub prawne, które korzystają z efektów działalności firmy.

W celu bieżącej oceny działalności firmy zgodnie z literaturą (Konieczny, 1983) można wówczas dokonać opisu jej funkcjonowania i określić stan firmy $\mathrm{S}(\mathrm{t}) \mathrm{w}$ chwili $\mathrm{t}$ na podstawie tzw. tablic identyfikacji matematycznej zaprezentowanej ogólnie w formie tabeli 1. 
Tahela 1. Tablica identyfikacji matematycznej systemu (podsystemu) (przyjęte w tabeli oznaczenia: $t, t_{o}$ oznaczają chwile na osi czasu, takie że $t>t_{o}$ ).

\begin{tabular}{|c|c|c|}
\hline \multirow{2}{*}{$\begin{array}{l}W(t)-\text { dochody } \\
\text { (przychody) } \\
\text { w chwili } t>t_{o}\end{array}$} & $\begin{array}{c}U\left(t_{o}\right) \text { - użyteczność } \\
\text { w chwili początkowej } t_{o}\end{array}$ & \multirow{2}{*}{$\begin{array}{c}V(t)-\text { nakłady (koszty) } \\
\text { w chwili } t>t_{o}\end{array}$} \\
\hline & $C-$ cenność & \\
\hline \multirow{2}{*}{$\begin{array}{l}A(t)-\text { zużycie } \\
\text { w chwili } t>t_{o}\end{array}$} & $R$-produktywność & \multirow{2}{*}{$\begin{array}{c}B(t)-\text { odnowa w chwili } \\
t>t_{o}\end{array}$} \\
\hline & $\begin{array}{c}Z\left(t_{o}\right) \text { - potencjał } \\
\text { początkowy w chwili } t_{o}\end{array}$ & \\
\hline
\end{tabular}

Źródło: opracowanie na podstawie (Konieczny, 1983; Śmiałkowska, 1985)

Wówczas ogólne równanie użyteczności dowolnego systemu (w tym firmy) w jego tzw. bliskim otoczeniu systemowym $\mathrm{w}$ dowolnej chwili $t>t_{o}$ jest zgodne ze wzorem (1):

$$
Z(t)=Z(0)-A(t)+R \times B(t)
$$

a równanie jego potencjału jest zgodne ze wzorem (2):

$$
U(t)=U(0)-V(t)+C \times W(t)
$$

gdzie symbole użyte we wzorach (1) i (2) opisano w tabeli 1.

Dodatkowo, zgodnie z literaturą (Konieczny, 1983; Śmiałkowska, 1985), dla systemu opisanego tablicą identyfikacji matematycznej (tab. 1) oraz funkcjami użyteczności i potencjału (wzory (1) i (2)), można określić w dowolnej chwili t możliwości tego systemu w jego otoczeniu biznesowym, oznaczone symbolem $M(t)$, a także jego potrzeby $P(t)$, w zakresie zabezpieczenia procesów realizowanych w tym systemie, $\mathrm{w}$ środki produkcji, energię czy w informację, zgodnie z następującymi wzorami:

gdzie:

$$
\begin{aligned}
& M(t)=Z(t) \\
& P(t)=U(t) / \mu(t)
\end{aligned}
$$

$\mu(t)$ - nakłady na zabezpieczenie realizacji procesów w rozważanym systemie.

Wówczas stan systemu „firma” w jej biznesowym otoczeniu w chwili t można zgodnie z przytoczoną wcześniej literaturą zdefiniować wzorem (5):

$$
S(t)=<M_{P Z}(t), M_{F}(t), P_{P Z}(t), P_{F}(t)>
$$

gdzie:

$M_{P Z}(t)$ - możliwości firmy w zakresie zasileń materialno-energio-technicznych i informacyjnych, zasilających (zabezpieczających) otoczenie biznesowe firmy, obliczone zgodnie ze wzorem (3),

$M_{F}(t)$ - możliwości firmy w zakresie finansów, obliczone zgodnie ze wzorem (3),

$P_{P Z}(t)$ - potrzeby firmy w zakresie zasileń materialno-energio-technicznych i informacyjnych, zabezpieczających firmę po to, by ona funkcjonowała, obliczone zgodnie ze wzorem (4),

$P_{F}(t)$ - potrzeby finansowe firmy, obliczone zgodnie ze wzorem (4).

Ponadto, stosując podstawy inżynierii systemów działania (Konieczny, 1983), możliwe jest wyprowadzenie teoretycznych zależności między firmą a jej biznesowym otoczeniem w chwili $t \mathrm{w}$ formie następujących wektorów wartości: 
- wskaźników wykorzystania możliwości firmy w jej biznesowym otoczeniu w chwili $t$, oznaczonych jako $\left.d^{F}(t)\right)$,

- wskaźników pokrycia potrzeb otoczenia biznesowego firmy w chwili $t$, oznaczonych symbolem $h^{F}(t)$,

obliczanych zgodnie z następującymi wzorami (6) i (7):

$$
\begin{aligned}
& d^{F}(t)=A(t) / M(t) \\
& h^{F}(t)=B(t) / P(t)
\end{aligned}
$$

gdzie symbole użyte we wzorach (6) i (7) opisano w tabeli 1 oraz we wzorach (1) i (2).

Dokładne dowody teoretyczne, a także algorytmy budowy tablicy identyfikacji matematycznej oraz wyznaczenia wskaźników $d^{F}(t)$ i $h^{F}(t)$ dla różnych rodzajów przepływów między firmą a jej biznesowym otoczeniem (np. przepływ ciągły, dyskretny, stacjonarny, niestacjonarny, itp.) zostały zaprezentowane w literaturze (Konieczny, 1983; Śmiałkowska, 1985, 2009). Z racji ograniczonego charakteru niniejszego artykuły zostały tu pominięte. Na podobnych zasadach z użyciem tablicy 1 oraz wzorów od (1) do (7) można zdefiniować użyteczność, potencjał, możliwości, potrzeby i współczynniki dopasowania wyróżnionych w firmie podsystemów czy procesów w celu oceny stanów tych podsystemów w dowolnej chwili t w ich otoczeniu biznesowym. Podział systemu - firma na podsystemy jest konieczny wówczas, gdy zarządzanie dynamiczne odnosi się nie tylko do całej firmy, ale również do ważnych i wybranych działów (dziedzin) funkcjonowania firmy istotnych biznesowo. Stosując powyższe zalecenia, można utworzyć uwarunkowany czasem (zależny od czasu) model funkcjonowania firmy i ewentualnie podsystemów firmy w jej otoczeniu biznesowym, co daje podstawy do zarządzania dynamicznego firmą. W kolejnych chwilach czasu znane są stany firmy:

$$
S\left(t_{0}\right), S\left(t_{0}+\Delta t\right), S\left(t_{0}+2 \times \Delta t\right), \ldots, S\left(t_{0}+k \times \Delta t\right)
$$

oraz wskaźniki dopasowania

gdzie $\Delta t>0$,

$$
\begin{aligned}
& d^{F}\left(t_{0}\right), d^{F}\left(t_{0}+\Delta t\right), d^{F}\left(t_{0}+2 \times \Delta t\right), \ldots, d^{F}\left(t_{0}+k \times \Delta t\right) \\
& h^{F}\left(t_{0}\right), h^{F}\left(t_{0}+\Delta t\right), h^{F}\left(t_{0}+2 \times \Delta t\right), \ldots, h^{F}\left(t_{0}+k \times \Delta t\right)
\end{aligned}
$$

$t_{0}$ - czas rozpoczęcia analizy stanu firmy,

$k$ - numer kolejnej chwili analizy stanów firmy.

tak jak to zilustrowano na rysunku 1. 


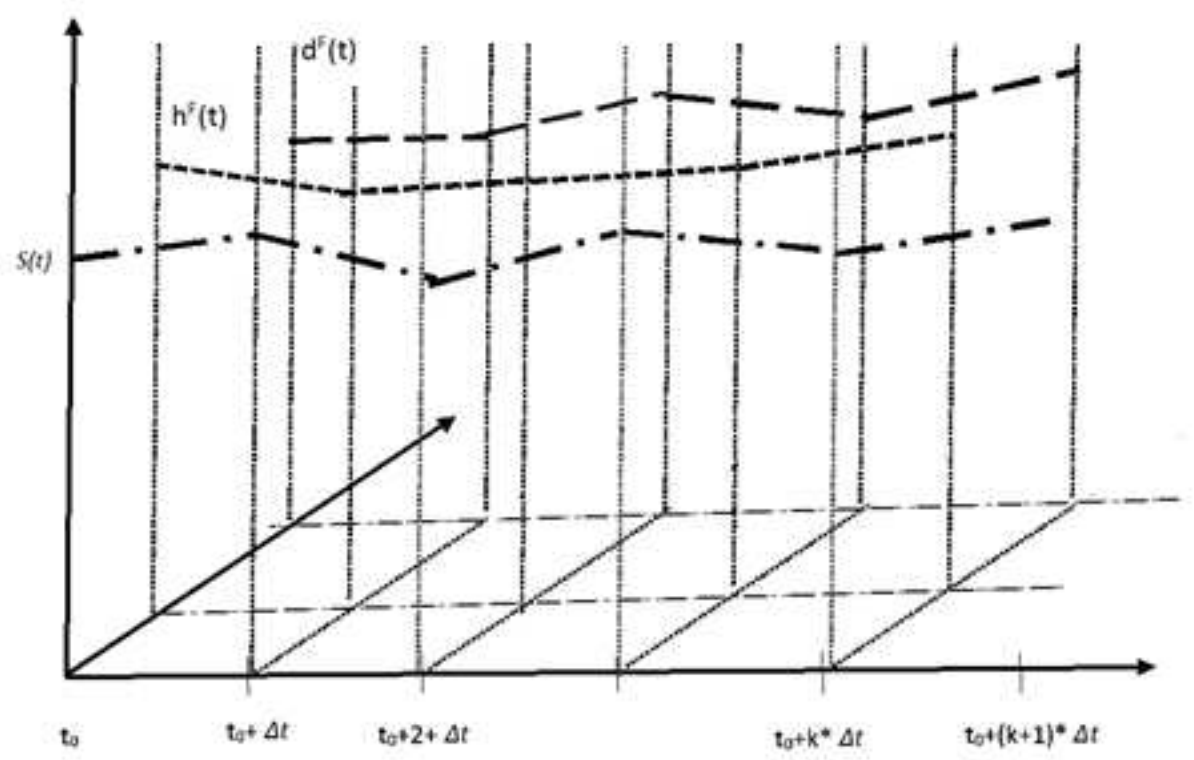

Rysunek 1. Ocena funkcjonowania firmy w jej otoczeniu biznesowym w czasie kolejnych chwil na osi czasu

Źródło: opracowanie własne.

Mogą one być podstawą podjęcia odpowiednich działań dostosowujących w chwili $t+(k+1) \times \Delta t$ firmę tak, by stan firmy w tej chwili był zgodny z jej biznesowym otoczeniem a wskaźniki dopasowania firmy do jej otoczenia odpowiednie w opinii eksperta. Aby wszystkie dane, niezbędne do oceny firmy w formie współczynników dopasowania $h^{F}(t)$ oraz $d^{F}(t)$ w jej biznesowym otoczeniu i opisane tablicami identyfikacji matematycznej, mogły być wykorzystane w zarządzaniu dynamicznym w dowolnej chwili czasu, niezbędne jest ich gromadzenie i udostępnianie w kolejnych chwilach. Funkcje takiego systemu, który gromadzi i udostępnia dane uwarunkowane czasem, pełnią hurtownie danych. Jednak by system z hurtownią danych dostarczał niezbędnych danych dla dynamicznego zarządzania, hurtownia powinna być zbudowana w sposób do tego odpowiedni. Koncepcję takiej hurtowni zaprezentowano w kolejnym rozdziale artykułu. 


\section{Adaptacyjna hurtownia danych w zarządzaniu dynamicznym firmą}

System $z$ hurtownią danych wspomagający zarządzanie dynamiczne powinien nie tylko gromadzić dane o funkcjonowaniu firmy w jej otoczeniu biznesowym w formie tablic identyfikacji matematycznej, użyteczności, potencjale, możliwościach i potrzebach, a także współczynnikach dopasowania $h^{F}(t)$ oraz $d^{F}(t)$, ale również powinien dostarczać danych do oceny strategii firmy, bo takie jest główne zadanie hurtowni danych. Dodatkowo systemy z hurtownią danych powinny umożliwiać adaptację strategii firmy do jej biznesowego otoczenia, a nie tylko gromadzić dane. Takie założenie obok potrzeby dostępu do danych niezbędnych do oceny dopasowania zarówno firmy do jej biznesowego otoczenia, jak również hurtowni do firmy mogą być na bieżąco gromadzone w dodatkowej warstwie metadanych hurtowni danych. Hurtownię danych, która spełnia powyższe założenia, nazwano adaptacyjną hurtownią danych, z racji konieczności modyfikacji jej struktur, gdy zmianie ulegnie strategia firmy, jej otoczenie biznesowe, lub gdy pojawią się nowe źródła danych wspomagające ocenę stanu firmy i poziomu realizacji strategii. Koncepcję takiej hurtowni danych zaprezentowano w literaturze (Śmiałkowska, 2009, 2011, 2014, 2015).

Podstawową własnością takiej hurtowni jest wielowersyjność danych w niej przechowywanych, a także gromadzenie w tzw. warstwie metadanych danych niezbędnych do wyznaczenia wszystkich wielkości zaprezentowanych w rozdziale 2, w formie dynamicznego modelu funkcjonowania firmy w jej biznesowym otoczeniu.

Dostęp administracyjny do warstwy metadanych hurtowni pozwala na dopasowywanie hurtowni do zmiennych potrzeb informacyjnych firmy w kolejnych okresach osi czasu, co w rezultacie prowadzi do uwiarygodnienia (podwyższenia jakości) danych, na podstawie których są budowane, modelowane i weryfikowane scenariusze biznesowe, będące podstawą badania skutków planowanych zmian w strategii firmy.

Hurtownia danych z tak zaprojektowanymi metadanymi umożliwi wówczas dodatkowo:

- bieżący pomiar i ocenę wskaźników dopasowania hurtowni do firmy na podstawie struktur wewnętrznych hurtowni,

- przeprojektowywanie hurtowni (zmianę jej struktury) i tworzenie nowej wersji w wielowersyjnej hurtowni danych (Śmiałkowska, 2009; Śmiałkowska i in., 2014), gdy jakość danych w niej przechowywanych jest niezadowalająca, a hurtownia nie jest dopasowana do firmy, dla której ją utworzono,

- permanentne zasilanie hurtowni danych nowymi źródłami danych, gdy tylko zaistnieje taka potrzeba, dzięki przyjętemu w tym modelu wielowersyjnemu charakterowi hurtowni,

- tworzenie obok tzw. rzeczywistych wersji danych w wielowersyjnym modelu hurtowni tzw. wersji alternatywnych, które umożliwiają przeprowadzanie symulacji scenariuszy biznesowych, analiz możliwych wariantów decyzji, przewidywania trendów z użyciem dostępnych w hurtowni narzędzi systemowych. 


\section{Model systemu $z$ adaptacyją̧ hurtownią danych i bazą wiedzy do wspomagania zarządzania dynamicznego firmą}

Bazując na zaproponowanej koncepcji adaptacyjnej hurtowni danych do wspomagania zarządzania firmą można utworzyć system z bazą wiedzy do wspomagania dynamicznego zarządzania firmą. Koncepcję takiego systemu zaprezentowano na rysunku 2. W skład tego systemu wchodzą następujące podsystemy:

- bazy wiedzy $B W$,

- systemu hurtowni danych $H D$,

- podsystemu $I W Z$ wspomagania zarządzania i prezentacji wyników,

- modułu IAWD oceny dopasowania hurtowni do potrzeb informacyjnych firmy.

Bazę wiedzy $B W$ w systemie do wspomagania zarządzania dynamicznego firmą tworzy się z wykorzystaniem następujących modułów:

- $M R F$ - modułu tworzenia i modyfikacji reprezentacji wiedzy o firmie w jej biznesowym otoczeniu,

- MRS - modułu tworzenia i modyfikacji wiedzy o strategii firmy,

- MRH - modułu tworzenia i adaptacji struktury hurtowni danych w formie kolejnej wersji struktur danych w hurtowni.

Źródłami zasilającymi hurtownię danych i bazę wiedzy w tym systemie są:

- tzw. operacyjne bazy danych i inne źródła zasilające hurtownię danych,

- wiedza wygenerowana $\mathrm{z}$ danych liczbowych zawartych $\mathrm{w}$ formie tablicy identyfikacji matematycznej firmy w jej otoczeniu biznesowym, zgodna z tabelą 1 dla podsystemu „firma” (tabela TIMF) wraz z procedurami obliczeń wykonywanych na tej tablicy (niezbędne do obliczenia współczynników dopasowania), dostarczana przez ekspertów do modułu $M R F$,

- wiedza wygenerowana ze strategii firmy w formie deklaratywnej (opisowej) lub proceduralnej (np. w formie wielokryterialnego modelu optymalizacji lub pareto optymalizacji albo równań bilansowych),

- wiedza pomocnicza wygenerowana z danych ilościowych i opisowych, o jakości danych przechowywanych w systemie z hurtownią danych dostarczana do modułu MRH bazująca na wiedzy eksperta - administratora hurtowni danych,

- wiedza wygenerowana $\mathrm{z}$ danych ilościowych zawartych w tablicy identyfikacji matematycznej zgodna z tabelą 1 dla podsystemu "hurtownia danych” (tzw. tablica TIMHD) w firmie wraz z procedurami obliczeń wykonywanych na tej tablicy (obliczanie współczynników dopasowania hurtowni danych do potrzeb firmy) dostarczana przez projektanta i analityka hurtowni danych (wiedza proceduralna) do modułu $M R H$. 


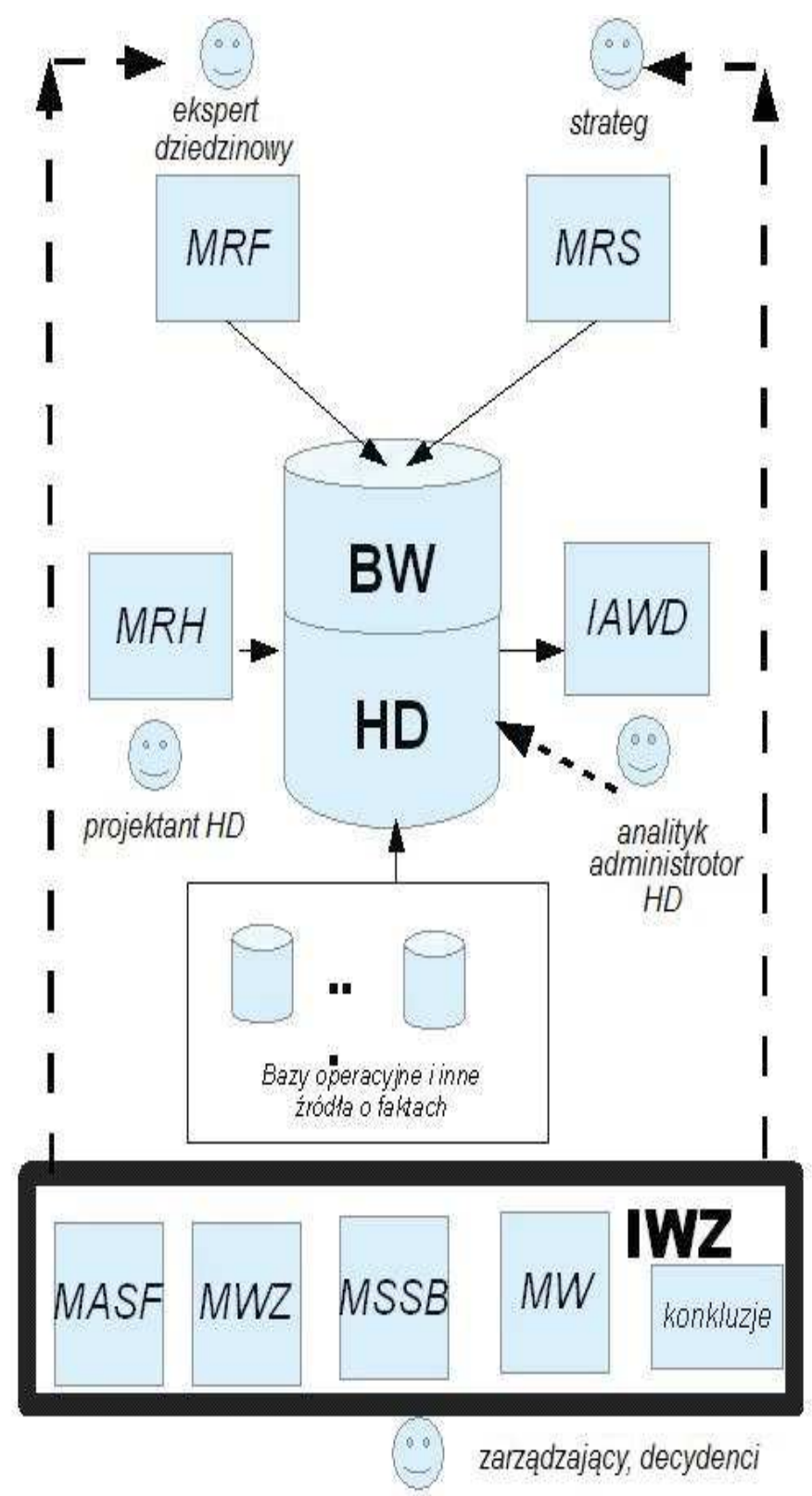

Rysunek 2. Struktura systemu z bazą wiedzy do wspomagania dynamicznego zarządzania firmą Źródło: opracowanie własne.

Na podstawie tych źródeł zasilających oraz modułów $M R F, M R S$ i $M R H$ zostaje utworzona hurtownia danych z bazą wiedzy. 
Przewiduje się, że wydobywanie wiedzy z danych tekstowych (np. opis strategii firmy, dane o jakości hurtowni danych) będzie realizowane jedną z dwóch głównych metod wydobywania wiedzy z tekstu, a mianowicie metodą uczenia maszynowego lub metodą bazującą na wiedzy eksperta. Uczenie maszynowe głównie opiera się na badaniu cech charakteryzujących strukturę tekstu (np. opisującego strategię firmy). W tym przypadku stosuje się modele przestrzeni wektorowych. W metodach ekstrakcji wiedzy opartych na wiedzy eksperta (np. w przypadku jakości danych w hurtowni) wykorzystuje się metody analizy znaczeniowej tekstu, stosując wzorce informacyjne i reguły dopasowania definiowane przez eksperta. Jedną z metod definiowania wzorców informacyjnych są ontologie, tworzone przez eksperta w języku OWL (ang. Web Ontology Language). Na podstawie wygenerowanych wzorców informacyjnych odpowiednich do wydobywania wiedzy z danych tekstowych (opisowych) możliwa jest weryfikacja oczekiwań.

Dane liczbowe (ujęte choćby w tablicach identyfikacji TIMF oraz TIMHD, a także dane o stanie firmy w jej biznesowym otoczeniu czy współczynniki wykorzystania możliwości i pokrycia potrzeb firmy czy hurtowni danych) pozwolą na wygenerowanie wiedzy w postaci reguł decyzyjnych. Oznacza to, że tak utworzona hurtownia danych z bazą wiedzy umożliwia wspomaganie dynamicznego zarządzania firmą za pomocą systemu $I W Z$, w którym wyróżnia się następujące moduły:

- MASF - moduł analizy stanu firmy w jej biznesowym otoczeniu na podstawie współczynników dopasowania obliczanych w kolejnych chwilach osi czasu przy pomocy tablic TIMF zawartych w bazie wiedzy,

- MSSB - moduł symulacji scenariuszy biznesowych (prognozowanie poprzez tworzenie tzw. alternatyw),

- $M W Z$ - moduł wykrywania stanów zagrożenia firmy,

- $M W$ - moduł wnioskowania automatycznego z danych tekstowych i numerycznych oraz wydruk konkluzji.

Zaprezentowana na rysunku 2 struktura systemu charakteryzuje się następującymi właściwościami:

- łączy w sobie modelowanie biznesowe z modelem danych,

- integruje możliwość tworzenia wersji z ewolucją schematu danych hurtowni,

- umożliwia automatyzację „strojenia” oraz dopasowania hurtowni danych do nowych potrzeb, dzięki przechowywaniu w warstwie metadanych hurtowni, ocen firmy w jej otoczeniu biznesowym oraz oceny strategii i hurtowni danych w kolejnych chwilach osi czasu,

- umożliwia analitykowi systemowemu, w formie interakcji, modyfikację modelu firmy a administratorowi hurtowni wygenerowanie nowej wersji rzeczywistej hurtowni danych za pomocą utworzonego w tym celu oprogramowania działającego na metadanych hurtowni,

- umożliwia dopasowanie hurtowni nawet do gwałtownych zmian stanu, celów, misji i strategii firmy w jej zmiennym otoczeniu, 
- dzięki tej koncepcji możliwe będzie modelowanie procesów biznesowych w firmie, prognozowanie skutków decyzji (symulacja i gry kierownicze), wczesne wykrywanie stanów niepożądanych w firmie (agenty programowe), a także dopasowanie struktury danych hurtowni do zmian w czasie potrzeb firmy. Pozwoli to na dynamiczne zarządzanie firmą.

\section{Podsumowanie}

Istotną cechą zaprezentowanego systemu jest takie wspomagania zarządzania, które nie tylko odnosi się do strategicznego poziomu procesów zarządczych, ale również do zmiennego w czasie stanu firmy, jej biznesowego otoczenia oraz dopasowania hurtowni do zmiennych w czasie potrzeb informacyjnych w firmie. Można go zaimplementować w firmach (przedsiębiorstwach) typu produkcyjnego lub usługowego i takich, które wymagają stosowania metod dynamicznego zarządzania. Implementacja takiego systemu wspomagającego zarządzanie nie jest prosta. Wymaga wieloetapowej realizacji:

1. wprowadzenia sposobu oceny strategii firmy (np. model optymalizacji lub paretooptymalizacji),

2. utworzenia hurtowni danych z tablicami identyfikacji TIMF oraz TIMHD,

3. gromadzenia danych w hurtowni oraz obserwacji wartości współczynników dopasowania i danych do oceny strategii firmy,

4. prognozowania skutków decyzji z użyciem mechanizmu wielowersyjności hurtowni, tworzenia scenariuszy biznesowych, symulacji przyszłych stanów firmy.

Ponadto gdy w ocenie analityka systemowego model danych w hurtowni w sensie współczynników dopasowania hurtowni do potrzeb firmy nie są odpowiednie do nowych potrzeb informacyjnych firmy, to podejmowany jest proces utworzenia nowej wersji modelu danych w hurtowni. Będzie to kolejny, piąty etap implementacji, po którym nastąpi nowy cykl etapów trzeciego i czwartego, dopóki nie wystąpi potrzeba wykonania ponownie etapu piątego.

\section{Literaturg}

Konieczny, J. (1983). Inżynieria systemów działania. Warszawa: WNT.

Lozano-Platonoff, A. (2009). Zarzadzanie dynamiczne. Warszawa: Difin SA.

Moczulski, W. (2000). Pozyskiwanie wiedzy deklaratywnej i proceduralnej. Proceedings of the Symposium on Methods of Artificial Intelligence in Mechanics and Mechanical Engineering, AI-MECH 2000. Gliwice, s. 55-69.

Śmiałkowska, B. (1995). Enterprise's identification modeling for integrated control. Międzynarodowa konferencja „Cybernetyka '85”. Warszawa.

Śmiałkowska, B. (2009). Dopasowanie hurtowni danych do zmiennych potrzeb informacyjnych przedsiębiorstwa. Szczecin: Wydawnictwo Uczelniane Zachodniopomorskiego Uniwersytetu Technologicznego w Szczecinie.

Śmiałkowska, B. (2011). Adaptacja hurtowni danych do zmiennych potrzeb informacyjnych przedsiębiorstwa. Studia Informatica Silesian University of Technology Press. Materiaty VII Konferencji Naukowej BDAS'2011, 32, 2B(97), 443-454. Gliwice. 
Śmiałkowska, B., Dudek, T. (2014). Zastosowanie adaptacyjnej hurtowni danych do modelowania scenariuszy biznesowych organizacji. Informatyka Ekonomiczna Business Informatics, 1(31), 355-37. Wrocław: Wydawnictwo Uniwersytetu Ekonomicznego we Wrocławiu.

Śmiałkowska, B. (2015). Wspomaganie procesów oceny i wyboru strategii firmy za pomocą adaptacyjnej hurtowni danych. Studia Informatica, 38, 203-214. Szczecin: Wydawnictwo Naukowe Uniwersytetu Szczecińskiego.

\section{DATA WAREHOUSE WITH KNOWLEDGE BASE FOR DYNAMICS MANAGEMENT OF ENTERPRISE}

\footnotetext{
KEYWORDS $\mid$ adaptive data warehouse, strategic decision support system, dynamics management of enterprise with knowledge base

\begin{tabular}{l|l} 
ABSTRACT & The paper presents the structure and method of adaptive and multiversion datawarehouse sys-
\end{tabular} tem, which is equipped with the mechanisms of adaptation and mechanism of the estimating of variables information about its functioning, historical and current data from activities of the enterprise and as data on the implementation of the enterprise's strategy. This datawersehouse system provides coefficients of adjustment of the enterprise's environment as well as data from simulation of projected business scenarios. This warehouse should be include a set of methods of inference, which will allow the derive knowledge to support dynamic management of enterprise and use declarative and procedural knowledge contained in this system.
} 